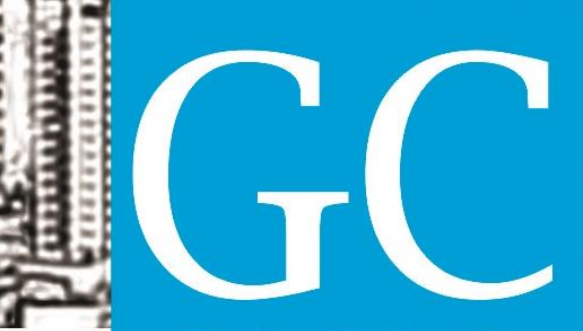

Revista Nacional de Gerenciamento de Cidades

\title{
ANÁLISE DE VIABILIDADE TÉCNICA DE VIAS CICLÁVEIS
}

\author{
Luzenira Alves Brasileiro ${ }^{1}$
}

Verônica de Freitas ${ }^{2}$

\begin{abstract}
RESUMO
Uma pista ou via ciclável é um espaço urbano ou faixa de tráfego destinada para a mobilidade de pessoas que utilizam bicicleta. O objetivo é realizar uma análise de viabilidade técnica de vias cicláveis na Estância Turística de Presidente Epitácio, Estado de São Paulo. A análise de viabilidade técnica é realizada com base na caracterização da demanda de transporte por bicicleta. A demanda por transporte é caracterizada pelo método sequencial: geração de viagens, distribuição de viagens, escolha modal e alocação de tráfego. A geração e a distribuição de viagens foram determinadas pela matriz origem/destino. A escolha modal dos habitantes da cidade foi determinada por entrevista, cuja amostra da população entrevistada foi calculada por método estatístico. A alocação do tráfego na rede de transporte foi realizada utilizando o software Google Maps. Os resultados mostram que é viável tecnicamente um sistema de vias cicláveis na cidade em estudo. Pode-se concluir que os segmentos existentes de vias cicláveis na cidade não são suficientes para atender a demanda e não estão interconectados entre si. Portanto, um sistema interconectado de vias cicláveis deve ser implantado, com base no estudo que mostra exatamente as rotas de transporte por bicicleta.
\end{abstract}

PALAVRAS-CHAVE: Bicicleta. Ciclovia. Transporte.

\section{TECHNICAL FEASIBILITY ANALYSIS OF BIKE LANES}

\section{ABSTRACT}

A track or cycling route is an urban space or lane of traffic destined for the mobility of people using bicycle. The goal is to analyze the technical feasibility of cycle routes in the tourist city of Presidente Epitácio, State of São Paulo. The technical feasibility analysis is based on the characterization of the demand for transport by bicycle. The demand for transport is characterized by the sequential method: trip generation, trip distribution, mode choice and traffic assignment. The

\footnotetext{
${ }_{1}^{1}$ Doutora em Engenharia de Transportes, UNESP - Docente. luzenira@dec.feis.unesp.br

${ }^{2}$ Arquiteta Urbanista e Mestra em Engenharia Civil, IFSP - Docente e Coordenadora de Curso Técnico Edificações. veronicaifsp@gmail.com / veronica@ifsp.edu.br
} 
generation and distribution of travel were determined by origin / destination matrix. The modal choice of the townsfolk was determined by interview and a sample of the population interviewed was calculated by statistical method. The allocation of traffic in the transport network was performed using the Google Maps software. The results show that it is technically feasible a system of cycle routes in the city under study. It can be concluded that the existing segments of cycle routes in the city are not enough to demand and are not interconnected with each other. Therefore, an interconnected system of cycle paths should be implemented, based on the study that shows exact routes of transportation by bicycle.

KEY-WORDS: Bicycle. Bike Lane. Transportation.

\section{ANÁLISIS DE VIABILIDAD TÉCNICA DE MANERA CARRILES PARA BICICLETAS}

\section{RESUMEN}

Una ruta de pista o el ciclismo es un espacio urbano o carril de tráfico destinado a la movilidad de las personas que utilizan la bicicleta. El objetivo es analizar la viabilidad técnica de las rutas para bicicletas en la ciudad turística de Presidente Epitácio, Estado de São Paulo. El análisis de factibilidad técnica se realiza en base a la caracterización de la demanda de transporte en bicicleta. La demanda de transporte se caracteriza por el método secuencial: la generación de viajes, distribución de viajes, elección del modo y la asignación de tráfico. La generación y distribución de viajes se determinaron por matriz de origen / destino. La elección modal de la gente del pueblo se determinó a través de entrevistas con una muestra de la población entrevistada se calculó por el método estadístico. La asignación de tráfico en la red de transporte se realizó utilizando el software de Google Maps. Los resultados muestran que es técnicamente factible sistema de rutas para bicicletas en la ciudad bajo estudio. Se puede concluir que los segmentos existentes de rutas para bicicletas en la ciudad no son suficientes para satisfacer la demanda y no están interconectados entre sí. Por lo tanto, un sistema interconectado de carriles bici se debe implementar, en base al estudio que muestra las rutas exactas de transporte en bicicleta.

PALABRAS-CLAVE: Bicicletas. Carril de bicicletas. Transporte.

\section{INTRODUÇÃO}

O gerenciamento de cidades deve ser função do planejamento urbano, que deve incluir o planejamento de transporte. A organização do espaço urbano é influenciada pelos modos de transportes, e a Revolução Industrial no Setor Automotivo foi um marco na configuração do desenho urbano. 


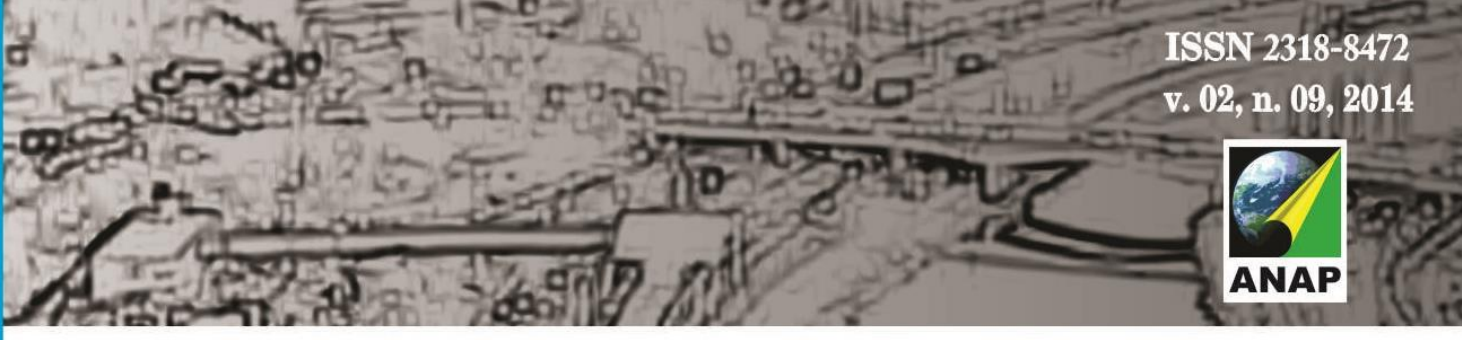

Revista Nacional de

Gerenciamento de Cidades

O progresso no setor automotivo, advindo da Revolução Industrial, de acordo com Benevolo (2009), trouxe algumas desvantagens de ordem física para as cidades, principalmente o congestionamento de trânsito; pois as ruas eram estreitas e não conseguiam conter o aumento do trânsito e as novas tecnologias de transporte.

Assim, têm-se a necessidade de separar os espaços urbanos, onde antes se misturava todos os modos de transporte. Atualmente, busca-se um desenho urbano, no qual os percursos sejam separados para os pedestres, bicicletas, automóveis e ônibus, com o propósito de evitar os conflitos de uso do solo.

O surgimento de novas tecnologias de transporte, na busca de um status social, altera a paisagem urbana, segundo Landim (2004). Assim, o planejamento urbano deve ter como meta o melhoramento da qualidade de vida da população urbana, de modo que as cidades comportem o aumento do tráfego.

Atualmente, o desafio dos gestores, planejadores e urbanistas é propor cidades sustentáveis, que favoreçam as trocas sociais, com qualidade de vida. O desenho urbano deve estar associado à funcionalidade da cidade e à logística de transporte, estimulando o uso dos modos não motorizados.

O transporte de passageiros é subdividido em transporte coletivo e transporte individual. $O$ transporte individual é tido como símbolo de liberdade e de afirmação de personalidade (PELLETIER E DELFANTE, 2000).

O planejamento do transporte urbano deve vir acompanhado da infraestrutura, conforme a necessidade de cada cidade. E, assim, adotar a melhor tecnologia, ou o conjunto de diversas tecnologias harmonizadas, para que a mobilidade urbana seja eficiente e segura.

Assim, este trabalho tem como objetivo precípuo apresentar os resultados de uma pesquisa realizada para identificar o principal modal que os passageiros utilizam nos deslocamentos, tendo como objeto de estudo a cidade de Presidente Epitácio, localizada no interior do Estado de São Paulo. 


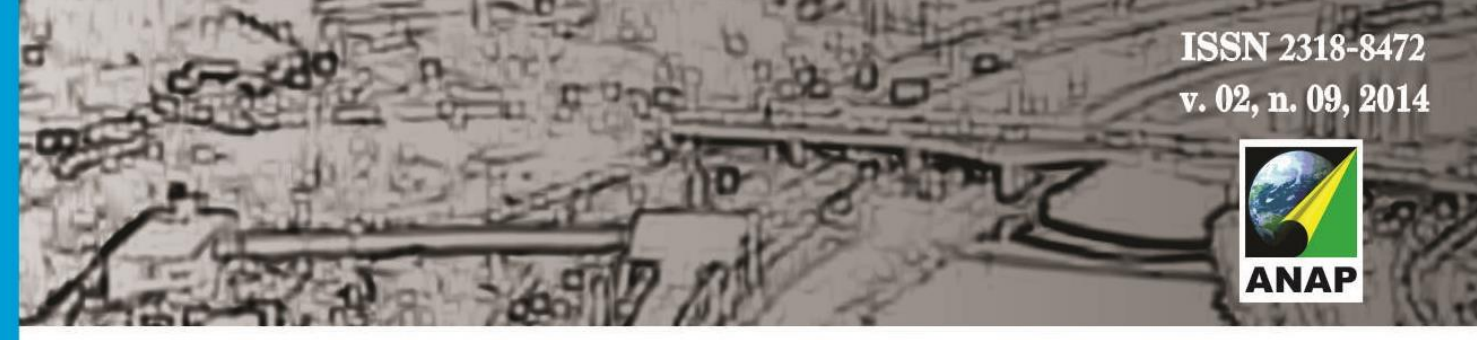

Revista Nacional de

Gerenciamento de Cidades

\section{TRANSPORTE URBANO DE PASSAGEIROS}

O sistema de transporte urbano contribui para a eficiência do sistema econômico da cidade como um todo; além de aumentar a qualidade de vida da população urbana, facilitar o acesso ao mercado de trabalho, possibilitar conforto nos deslocamentos e aumentar o tempo para lazer e descanso (NARDES, 2007).

O transporte de pessoas é algo complexo, pois o motivo e a natureza da viagem apresentam origem e destino diversificados. Assim, um sistema eficiente de transporte de passageiros é o mínimo que a cidade deve oferecer para que a mesma tenha um bom funcionamento.

O transporte urbano de passageiros pode ser classificado em transporte motorizado e transporte não motorizado. Segue alguns modos do transporte motorizado e não motorizado respectivamente: motocicleta, automóvel e ônibus e modo a pé e bicicleta.

Geralmente, as pessoas consideram o automóvel como uma alternativa para obter melhor qualidade de vida, devido a sua flexibilidade de rota e horário. Isto faz com que este bem se torne alvo de consumo da população, e ainda receba incentivos do governo.

Esse fato provoca o crescente e exacerbado uso do automóvel, contribuindo com uma série de fatores prejudiciais para a saúde do ser humano e para o convívio do homem no meio ambiente (SILVA, 2009).

Portanto, as estratégias de políticas urbanas devem adequar e racionalizar o uso da tecnologia motorizada e incentivar o uso dos transportes coletivos e dos transportes não motorizados pelos passageiros.

O transporte de passageiros deve ser integrador, acessível, eficiente e ser sustentável. Mediante estas circunstâncias, torna-se necessário planejar sistemas de transporte voltados as tecnologias não motorizadas, protegendo o ambiente e favorecendo a mobilidade urbana. 


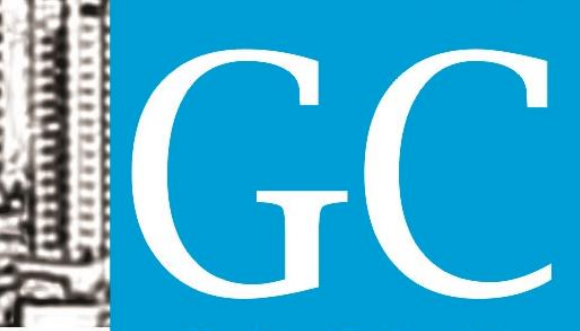

\section{Revista Nacional de}

Gerenciamento de Cidades

Para iniciar o cálculo estatístico é necessário conhecer o número de habitantes na cidade. O Quadro 2 apresenta dados numéricos da população de Presidente Epitácio/SP, mostrando um total de 41.511 habitantes, que estão separados em 20.312 habitantes para a população masculina e 21.199 habitantes para a população feminina.

De posse dessa informação definiu-se os critérios estatísticos e o cálculo da amostragem representativa considerou cada elemento da população tendo a mesma possibilidade de ser incluído na amostra.

\section{Quadro 2 - População da cidade de Presidente Epitácio}

\begin{tabular}{|l|l|c|}
\hline & & 2011 \\
\hline & População e Estatisticas Vitais - População Masculina & 20.312 \\
\hline $\begin{array}{c}3541307- \\
\begin{array}{c}\text { Presidente } \\
\text { Epitácio }\end{array}\end{array}$ & População e Estatisticas Vitais - População Feminina & 21.199 \\
\hline & População e Estatisticas Vitais - Grau de Urbanização (Em \%) & 41.511 \\
\hline & População e Estatisticas Vitais - População & \\
\hline & População e Estatisticas Vitais - População Urbana & \\
\hline
\end{tabular}

Fonte: Fundação Sistema Estadual de Análise de Dados de São Paulo - SEADE

A escolha modal dos habitantes da cidade foi determinada por entrevista, cuja amostra da população entrevistada foi calculada por método estatístico da Amostragem Aleatória Simples (AAS), como mostra a Figura 1, por meio de planilha eletrônica $E x c e l^{3}$. A geração e a distribuição de viagens foram determinadas pelas matrizes origem e destino.

Figura 1 - Número de questionários a serem aplicados

\footnotetext{
${ }^{3}$ Marca registrada da Microsoft Corporation. Licença disponível no IFSP - Instituto Federal de Ciência e Tecnologia - Campus de Presidente Epitácio.
} 


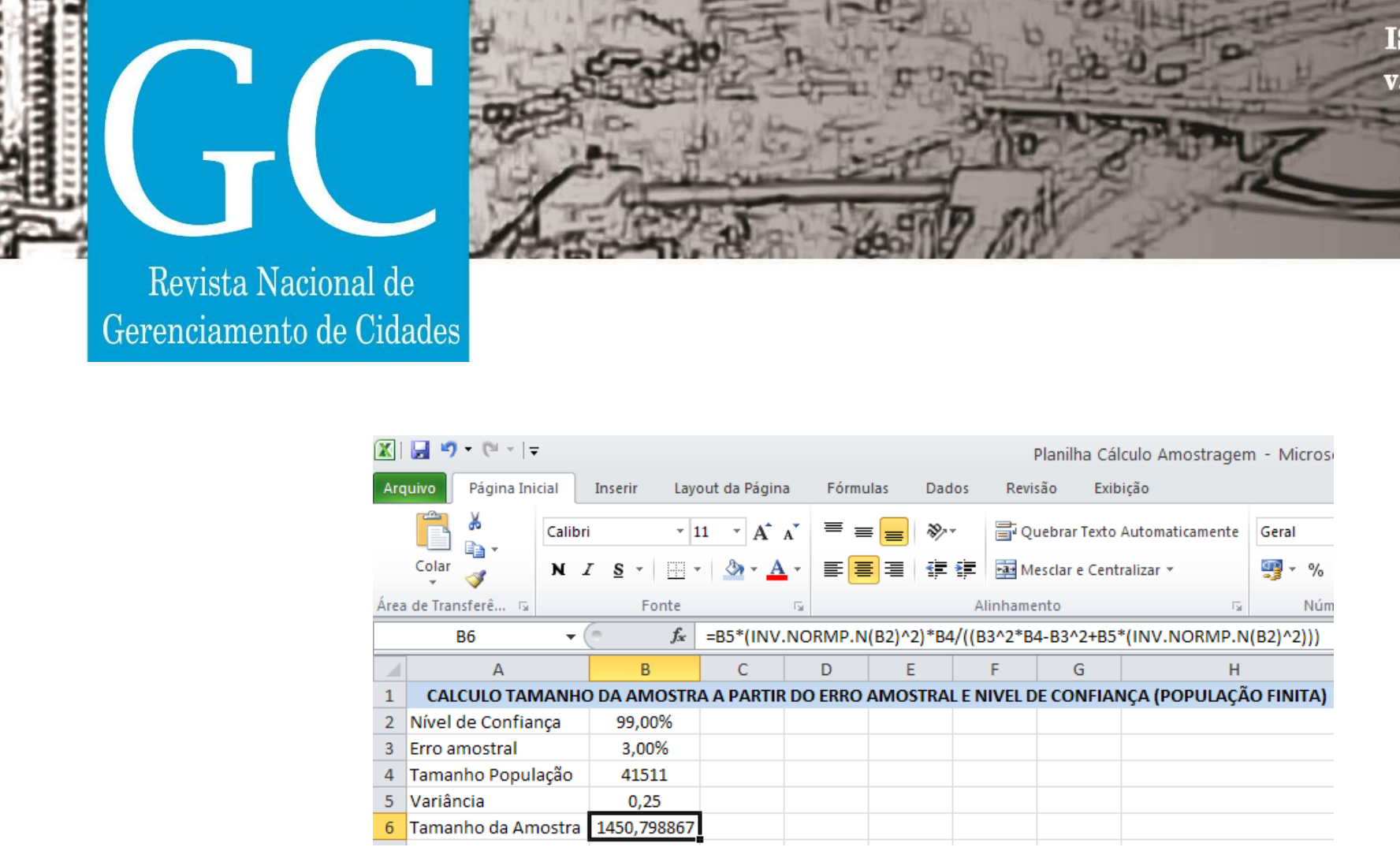

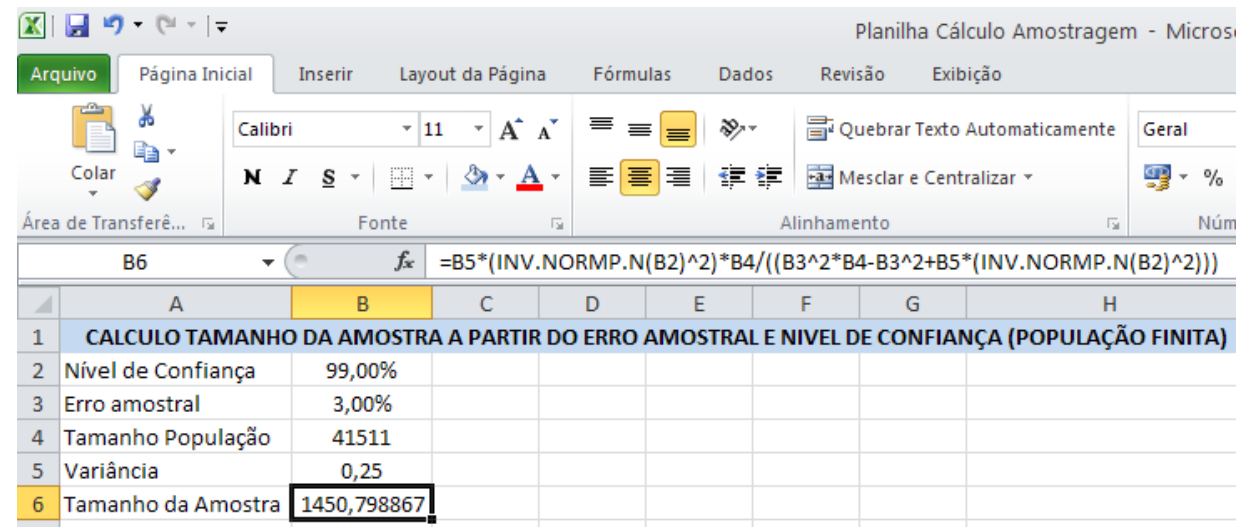

Fonte: Software Microsoft $\circledast$ Excel

De acordo com esses dados estatísticos, concluiu-se que se deve entrevistar no mínimo 1451 pessoas na cidade. Quanto à alocação do tráfego na rede de transporte foi realizada utilizando o software Google Maps ${ }^{4}$. Esse programa permite visualizar os percursos diretamente no mapa da cidade.

\section{CARACTERIZAÇÃO DO ESTUDO DE CASO}

A cidade de Presidente Epitácio/SP está localizada à margem do rio federal Paraná, na divisa do Estado do Mato Grosso do Sul. O clima é tropical úmido e o relevo é plano. A renda média da população é relativamente baixa, urbe de pequeno porte, com 41.511 habitantes.

A cidade em estudo apresenta características típicas do sistema de transporte por bicicleta. Atualmente, a frota de veículos motorizados é composta por 10.593 automóveis, 7.145 motocicletas, outras categorias motorizadas 3005. E na categoria não motorizada estima-se 30.000 bicicletas (PMPE, 2014).

Apesar da grande quantidade de bicicletas a cidade carece de infraestrutura cicloviária, os segmentos existentes de vias cicláveis são insuficientes para atender

\footnotetext{
${ }^{4}$ Marca registrada Google Maps. Licença software livre.
} 


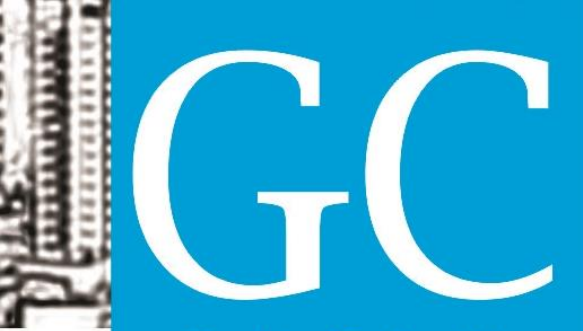

Revista Nacional de

Gerenciamento de Cidades

Figura 2: Caracterização de demanda por transporte de passageiros

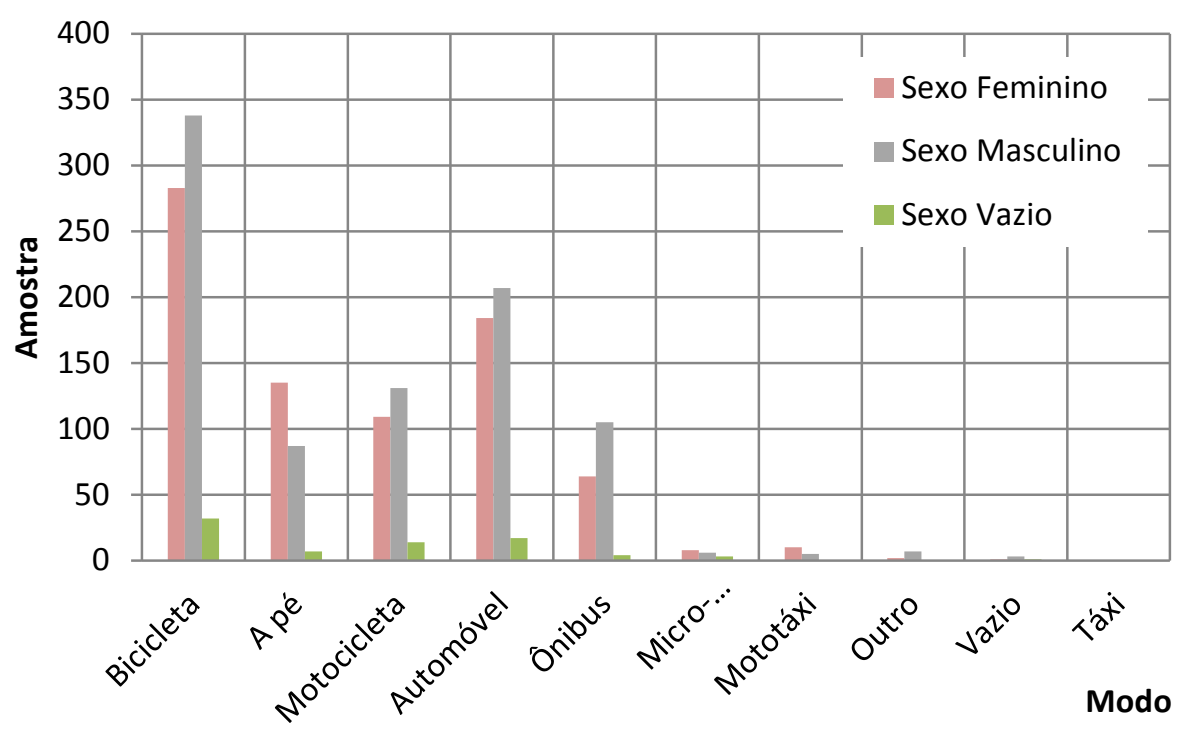

Fonte: autoria própria, 2014.

$\mathrm{Na}$ Erro! Fonte de referência não encontrada.2, visualiza-se também que o sexo masculino predomina no uso dos diversos modos, as únicas tecnologias que as mulheres utilizam mais que os homens são: a pé (135), mototáxi (10) e microônibus (8).

A questão da divisão entre o sexo masculino e feminino é um aspecto importante a ser considerado, pois alguns autores relatam que os homens utilizam mais a bicicleta do que as mulheres, devido as seguintes questões: maior resistência física, maior segurança para enfrentar o trânsito na hora de pedalar e acredita-se também que as mulheres são mais vulneráveis a assaltos.

Logo, a vulnerabilidade em relação à segurança urbana não é um fator determinante para a escolha do modo, já que o fato de caminhar também deixa a mulher mais exposta. Todavia, acredita-se que isto ocorra, pelo fato do estudo de caso dessa pesquisa acontecer em uma cidade de pequeno porte, em que seja verificado um menor número de ocorrências policiais relacionadas a essa questão. 


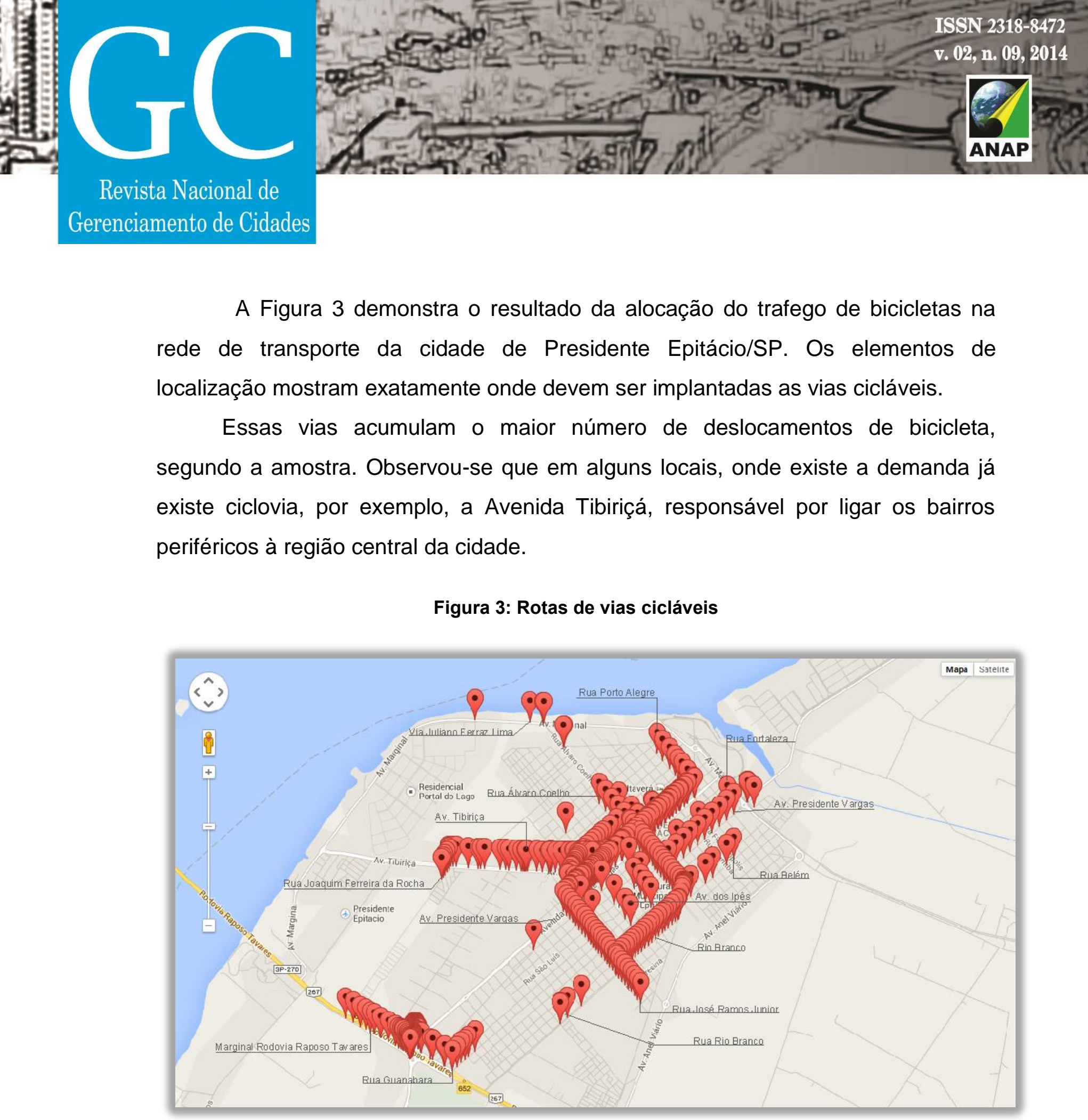

Revista Nacional de

Gerenciamento de Cidades

A Figura 3 demonstra o resultado da alocação do trafego de bicicletas na rede de transporte da cidade de Presidente Epitácio/SP. Os elementos de localização mostram exatamente onde devem ser implantadas as vias cicláveis.

Essas vias acumulam o maior número de deslocamentos de bicicleta, segundo a amostra. Observou-se que em alguns locais, onde existe a demanda já existe ciclovia, por exemplo, a Avenida Tibiriçá, responsável por ligar os bairros periféricos à região central da cidade.

\section{Figura 3: Rotas de vias cicláveis}

Fonte: autoria própria, 2014.

Destaque para a Marginal da Rodovia Raposo Tavares que acessa o Distrito Industrial; a Rua Rio Branco, Rua José Ramos Junior, Rua Pernambuco que acessam as principais instituições de ensino.

A Rua Álvaro Coelho e a Via Juliano Ferraz Lima com acesso a Orla Fluvial, destaque para a recreação. A Avenida Presidente Vargas local onde se concentra o 


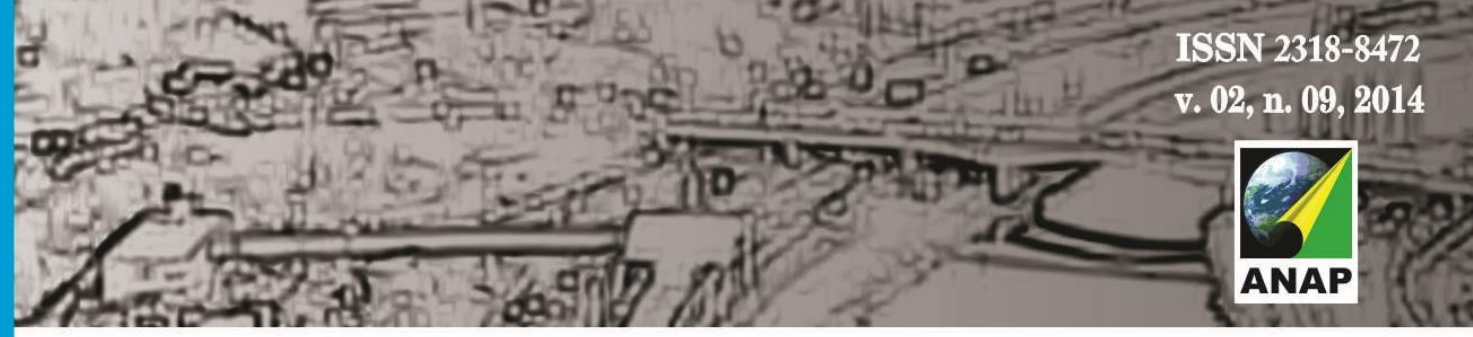

Revista Nacional de Gerenciamento de Cidades

bicicleta na cidade, valorizando a implantação da infraestrutura cicloviária, conforme as características socioeconômicas e físico-funcionais da urbe.

De modo a promover uma cidade saudável, pois o setor de transportes atual do país tem problemas ambientais, sociais e energéticos; enquanto que a bicicleta apresenta inúmeros benefícios, para o meio ambiente, para a saúde e economia do ciclista.

Acredita-se que estas medidas irão contribuir para a redução dos índices de acidentes, fornecer segurança pessoal para o ciclista e sua bicicleta, melhorar a qualidade de vida dos ciclistas e dos habitantes, atrair turistas e evitar a segregação urbana.

Em suma, a obtenção dos principais trajetos direcionará o gestor a diversas ações, tais como: propor novas vias cicláveis, gerenciar a intermodalidade de transporte, restaurar as ciclovias existentes e adaptar ciclofaixas; mas, sempre em concordância com as questões ambientais e com as leis de trânsito.

\section{REFERÊNCIAS}

ABREU, Allan de; FERRO, Bruno. Rio Preto de 2030 terá até metrô. DiárioWeb. São José do Rio Preto, São Paulo, 09 set. 2013. Disponível em: <http://www.diarioweb.com.br/novoportal/Noticias/Cidades/148433,,Rio+Preto+de+2030+tera+ate+me tro.aspx>. Acesso em: 09 set. 2013.

BENEVOLO, Leonardo. História da Cidade. São Paulo: Perspectiva, 2009. 183p.

INSTITUTO DE ENERGIA E MEIO AMBIENTE (IEMA); TC URBES. A Bicicleta e as Cidades: Como Inserir a Bicicleta na Política de Mobilidade Urbana. $2^{\underline{a}}$ Edição, São Paulo, 2012. 230p.

LANDIM, Paula da Cruz. Desenho de Paisagem Urbana: As Cidades do Interior Paulista. São Paulo: UNESP, 2004. 113p.

NARDES, Augusto. Desenvolvimento de Infraestrutura de Transportes no Brasil: Perspectivas e Desafios. Brasília, Distrito Federal. Tribunal de Contas da União, 2007. 180p.

PELLETIER, Jean; DELFANTE, Charles. Cidades e Urbanismo no Mundo. Lisboa: Instituto Piaget, 2000. 50p.

PREFEITURA MUNICIPAL DE PRESIDENTE EPITÁCIO (PMPE). Frota de Veículos Pariculares. Departamento Municipal de Trânsito, 2014. 13p. 
